Published in final edited form as:

Bioconjug Chem. 2007 ; 18(3): 607-609. doi:10.1021/bc060319u.

\title{
Peptide Beacons: A New Design for Polypeptide-Based Optical Biosensors
}

\author{
Kenneth J. Oh ${ }^{1}$, Kevin J. Cash ${ }^{2}$, Verena Hugenberg ${ }^{1}$, and Kevin W. Plaxco ${ }^{1,3},{ }^{*}$ \\ 1 Department of Chemistry and Biochemistry, University of California, Santa Barbara, Santa Barbara, CA \\ 93106 \\ 2Department of Chemical Engineering, University of California, Santa Barbara, Santa Barbara, CA 93106 \\ 3Interdepartmental Program in Biomolecular Science and Engineering, University of California, Santa \\ Barbara, Santa Barbara, CA 93106
}

\section{Abstract}

Phage display and other in vitro selection techniques produce short polypeptides that tightly and specifically bind to any of a wide range of macromolecular targets. Here we demonstrate a potentially general means of converting such polypeptides into optical biosensors. The sensing architecture we have developed, termed peptide beacons, is based on the observation that, whereas short peptides are almost invariably unfolded and highly dynamic, they become rigid when complexed to their target. Using this effect to segregate a long-lived fluorophore from an electron transfer-based contact quencher, both covalently attached to the peptide, we have produced a robust optical sensor for antiHIV antibodies. The binding-induced segregation of the fluorophore-quencher pair produces a sixfold increase in sensor emission, thus allowing us to readily detect as low as $\sim 250 \mathrm{pM}$ of the target antibody. Because the sensor is based on binding-induced folding and a visible-light fluorophore, it is sufficiently selective to work directly in complex, contaminant-ridden samples such as saliva and blood.

\section{Introduction}

Molecular beacons (1) (MBs), stem-loop DNAs that undergo a conformational change upon target binding, have proven useful for the optical (2) and electronic (3) detection of oligonucleotides. In the absence of target, the MB stem holds terminally attached quencher and fluorophore moieties in proximity, reducing emission. Upon target binding the stem is disrupted, segregating the termini and producing a large, readily measured increase in fluorescence emission (4). While sensitive and convenient, however, the generality of the MB approach has proven limited, with only the detection of oligonucleotide-binding targets reported to date. Given the number of analytes, such as antibodies (5), better recognized by polypeptides, the development of polypeptide-based MB analogs could thus significantly extend the utility of this promising approach.

The development of polypeptide-based MB analogs has been hampered by the fact that polypeptides do not form stable stem-loop structures (6). We have, however, recently demonstrated a solution to this problem in a new class of sensors, termed peptide beacons (PB), that exploit the observation that, while unbound polypeptides are highly dynamic, their structure becomes fixed upon binding to a macromolecular target. Using this effect to segregate

*kwp@chem.ucsb.edu. 
pyrene excimers attached to the termini of sensing polypeptides, we have recently extended the MB approach to polypeptide-based detection (7).

Pyrene excimer-based peptide beacons achieve sub-nanomolar detection limits and excellent specificity when tested in contaminant-free buffer. They largely fail, however, when deployed in complex, contaminant ridden samples due to the relatively poor optical characteristics of pyrene: pyrene excitation occurs in the UV, which results in significant background fluorescence, and the signal gain of pyrene-based PBs is only two-fold (7). Here we describe an alternative $\mathrm{PB}$ architecture that, in contrast, is characterized by visible-light excitation and significantly improved signal gain (Fig. 1).

\section{Results}

We have synthesized a new PB architecture based on a highly antigenic (8), six-residue epitope from the HIV protein $\mathrm{p} 17$. As is true with almost all unstructured polypeptides, the two ends of the unbound epitope collide on a timescale of $<100 \mathrm{~ns}(9)$. When bound to its target antibody, however, the epitope adopts a rigid, modestly extended conformation (10). We also employed a fluorophore, ruthenium (II) bisbipyridine-phenanthroline, that exhibits a $\sim 800$ ns lifetime, exciting in the visible, and exhibiting a $160 \mathrm{~nm}$ Stokes shift (11). Optimization of the PB signal change upon binding requires that quenching be efficiently halted upon even the smallest binding induced segregation, requiring in turn that we employ electron transfer-based mechanism that decreases exponentially with distance. To this end we employed the electron accepting quencher methyl viologen. Our new PB thus consists of a ruthenium/viologen pair conjugated to the termini of the p17 epitope via cysteine linkers (fig. 1).

The emission of our new PB architecture is enhanced six-fold upon addition of its target antibody (Fig. 2). The signal gain and emissivity of the PB allow us to readily quantify the target antibody at concentrations as low as $\sim 250 \mathrm{pM}$, close to the $200 \mathrm{pM}$ dissociation constant reported for the un-modified polypeptide (12). Finally, the gain of the PB is independent of its concentration (data not shown), indicating that the observed quenching is intramolecular.

The PB mechanism is linked to a binding-specific conformational change and thus the sensor should be selective against contaminants. Nevertheless, the background fluorescence present in realistically complex samples generally limits the sensitivity of optical sensors. This problem is minimized here by the use of a visible light fluorophore with a $160 \mathrm{~nm}$ Stokes shift, attributes that allow us to detect the target antibody even in complex, contaminant-ridden samples, (such as serum and saliva; Fig. 3), albeit with poorer detection limits than observed in buffer. Of note, the signal-gain observed in serum is similar to that observed in buffer, confirming that the sensor is unaffected by any of the hundreds of proteins contaminating these materials (13).

\section{Discussion}

Here we have demonstrated a novel biosensor that is sensitive, operationally convenient, and selective enough to be employed directly in complex, contaminant-ridden samples. The sensitivity of PBs is competitive with absorption-based, label-free sensing approaches, such as surface plasmon resonance and quartz crystal microbalances (14). In contrast to these approaches, however, the PB architecture combines this sensitivity with excellent selectivity: because signaling is linked to a specific, binding-induced conformational change the PB approach is relatively insensitive to the non-specific binding that typically complicates adsorption-based sensing schemes (15). Additionally, the fluorophore we have employed excites in the visible and exhibits a large Stokes shift, reducing background fluorescence and allowing for deployment in clinical samples. The described PB approach also appears to be a 
more general platform than previous peptide-based optical sensing approaches (16-17) in that PBs neither require that binding specifically sequester a quencher (18), nor do they rely upon tryptophan fluorescence, which is difficult to monitor in the presence of typical contaminants (19). (Of note, we do not observe any significant quenching when tryptophan is titrated against a model ruthenium complex, suggesting that the approach is not limited to tryptophan-free polypeptides -data not shown). Lastly, while the described PB does not exhibit the low picomolar to femtomolar sensitivities reported for the most highly optimized Western Blot and ELISA assays (20-21), the approach does not require the labile reagents or cumbersome equipment and batch processing of these techniques.

The PB sensing strategy may be general as its only requirements are that: intramolecular collisions in the unbound polypeptide are rapid and intermolecular collisions in the bound state are slow relative to the excited-state lifetime of the fluorophore, that the bound state of the peptide segregates the fluorophore/quencher pair by at least a few angströms, and that the fluorophore and quencher do not disrupt binding. Given that the majority of small peptides are highly dynamic relative to the lifetime of our ruthenium fluorophore $(9,11)$, and given the ready elucidation of novel polypeptide-based recognition elements by phage and bacterial display techniques (22), it appears that the PB approach described here will be applicable to a wide range of macromolecular targets.

\section{Supplementary Material}

Refer to Web version on PubMed Central for supplementary material.

\section{Acknowledgements}

This work was supported by the NIH Grant EB002046 and the UCBioSTAR program. This work made use of MRL Central Facilities supported by the MRSEC Program of the NSF under award No. DMR05-20415.

\section{References}

1. Tyagi S, Kramer FR. Molecular Beacons: Probes that Fluoresce upon Hybridization. Nat Biotechnol 1996;14:303-308. [PubMed: 9630890]

2. Kuhn H, Demidov VV, Coull JM, Fiandaca MJ, Gildea BD, Frank-Kamenetskii MD. Hybridization of DNA and PNA Molecular Beacons to Single-Stranded and Double-Stranded DNA Targets. J Am Chem Soc 2002;124:1097-1103. [PubMed: 11829619]

3. Fan C, Plaxco KW, Heeger AJ. Electrochemical interrogation of conformational changes as a reagentless method for the sequence-specific detection of DNA. Proc Natl Acad Sci USA 2003;100:9134-9137. [PubMed: 12867594]

4. Fang X, Liu X, Schuster S, Tan W. Designing a Novel Molecular Beacon for Surface-Immobilized DNA Hybridization Studies. J Am Chem Soc 1999;121:2921-2922.

5. Winter G, Griffiths AD, Hawkins RE, Hoogenboom HR. Making Antibodies by Phage Display Technology. Annu Rev Immunol 1994;12:433-455. [PubMed: 8011287]

6. Pincus MR. Identification of structured peptide segments in folding proteins. Biopolymers 1992;32:347-351. [PubMed: 1320417]

7. Oh KJ, Cash KJ, Plaxco KW. Excimer-Based Peptide Beacons: A Convenient Experimental Approach for Monitoring Polypeptide-Protein and Polypeptide-Oligonucleotide Interactions. J Am Chem Soc 2006;128:14018-14019. [PubMed: 17061871]

8. Papsidero LD, Sheu M, Ruscetti FW. Human immunodeficiency virus type 1-neutralizing monoclonal antibodies which react with p17 core protein: characterization and epitope mapping. J Virol 1989;63:267-272. [PubMed: 2462060]

9. Lapidus LJ, Eaton WA, Hofrichter J. Measuring the rate of intramolecular contact formation in polypeptides. Proc Natl Acad Sci U S A 2000;97:7220-7225. [PubMed: 10860987] 
10. Massiah MA, Starich MR, Paschall C, Summers MF, Christensen AM, Sundquist WI. Threedimensional Structure of the Human Immunodeficiency Virus Type 1 Matrix Protein. J Mol Biol 1994;244:198-223. [PubMed: 7966331]

11. Castellano FN, Dattelbaum JD, Lakowicz JR. Long-Lifetime Ru(II) Complexes as Labeling Reagents for Sulfhydryl Groups. Anal Biochem 1998;255:165-170. [PubMed: 9451499]

12. Ota A, Ueda S. Evaluation of the affinity measurement of anti-HIV-1 p17 monoclonal antibody by BIAcore. Hybridoma 1998;17:471-477. [PubMed: 9873993]

13. Adkins JN, Varnum SM, Auberry KJ, Moore RJ, Angell NH, Smith RD, Springer DL, Pounds JG. Toward a Human Blood Serum Proteome: Analysis By Multidimensional Separation Coupled With Mass Spectrometry. Mol Cell Proteom 2002;1:947-955.

14. Kößlinger C, Uttenthaler E, Drost S, Aberl F, Wolf H, Brink G, Stanglmaier A, Sackmann E. Comparison of the QCM and the SPR method for surface studies and immunological applications. Sensors and Actuators B 1995;24:107-112.

15. Asanov AN, Wilson WW, Oldham PB. Regenerable Biosensor Platform: A Total Internal Reflection Fluorescence Cell with Electrochemical Control. Anal Chem 1998;70:1156-1163. [PubMed: 9530005]

16. Kohn JE, Plaxco KW. Engineering a signal transduction mechanism for protein-based biosensors. Proc Natl Acad Sci U S A 2005;102:10841-10845. [PubMed: 16046542]

17. Neuweiler H, Schultz A, Vaiana AC, Smith JC, Kaul S, Wolfrum J, Sauer M. Detection of Individual p53-Autoantibodies by Using Quenched Peptide-Based Molecular Probes. Angew Chem Int Ed 2002;41:4769-4773.

18. Jean JM, Clerte C, Hall KB. Global and local dynamics of the human U1A protein determined by tryptophan fluorescence. Protein Sci 1999;8:2110-2120. [PubMed: 10548057]

19. Lotte K, Plessow R, Brockhinke A. Static and time-resolved fluorescence investigations of tryptophan analogues - a solvent study. Photochem Photobio Sci 2004;3:348-359.

20. Regnault V, Arvieux J, Vallar L, Lecompte T. Immunopurification of human $\beta 2$-glycoprotein I with a monoclonal antibody selected for its binding kinetics using a surface plasmon resonance biosensor. J Immunol Methods 1998;211:191-197. [PubMed: 9617843]

21. Rayevskaya G, Pilipenko VG, Tkacikova L, Spivak NY, Mikula I, Chumak RM. Characterization of the Third Generation Enzyme Immunoassay IEA HIV1/2 III for the Detection of Anti HIV Specific Antibodies in Human Sera. Folia Microbiol 2000;45:577-580. [PubMed: 11501427]

22. Bessette PH, Rice JJ, Daugherty PS. Rapid isolation of high-affinity protein binding peptides using bacterial display. Protein Engineering, Design \& Selection 2004;17:731-739.

\section{Abbreviations}

HIV

human immunodeficiency virus

MB

molecular beacon

PB

peptide beacon

ELISA

enzyme-linked immunosorbent assay 

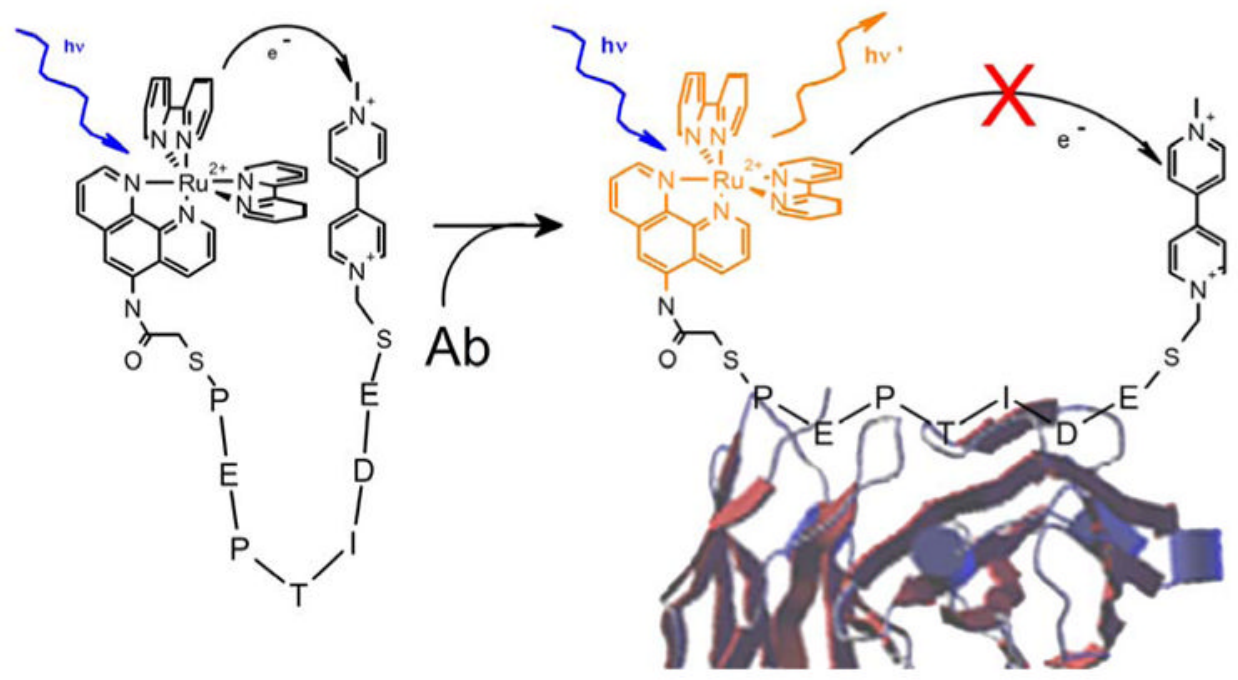

Figure 1.

The PB architecture is comprised of a long-lived fluorophore, an electron-accepting quencher and a recognition peptide. In the absence of target (left), intramolecular collisions allow for fluorescence quenching. Upon target binding (right), the fluorophore is segregated from the quencher, preventing electron transfer and enhancing fluorescence. 


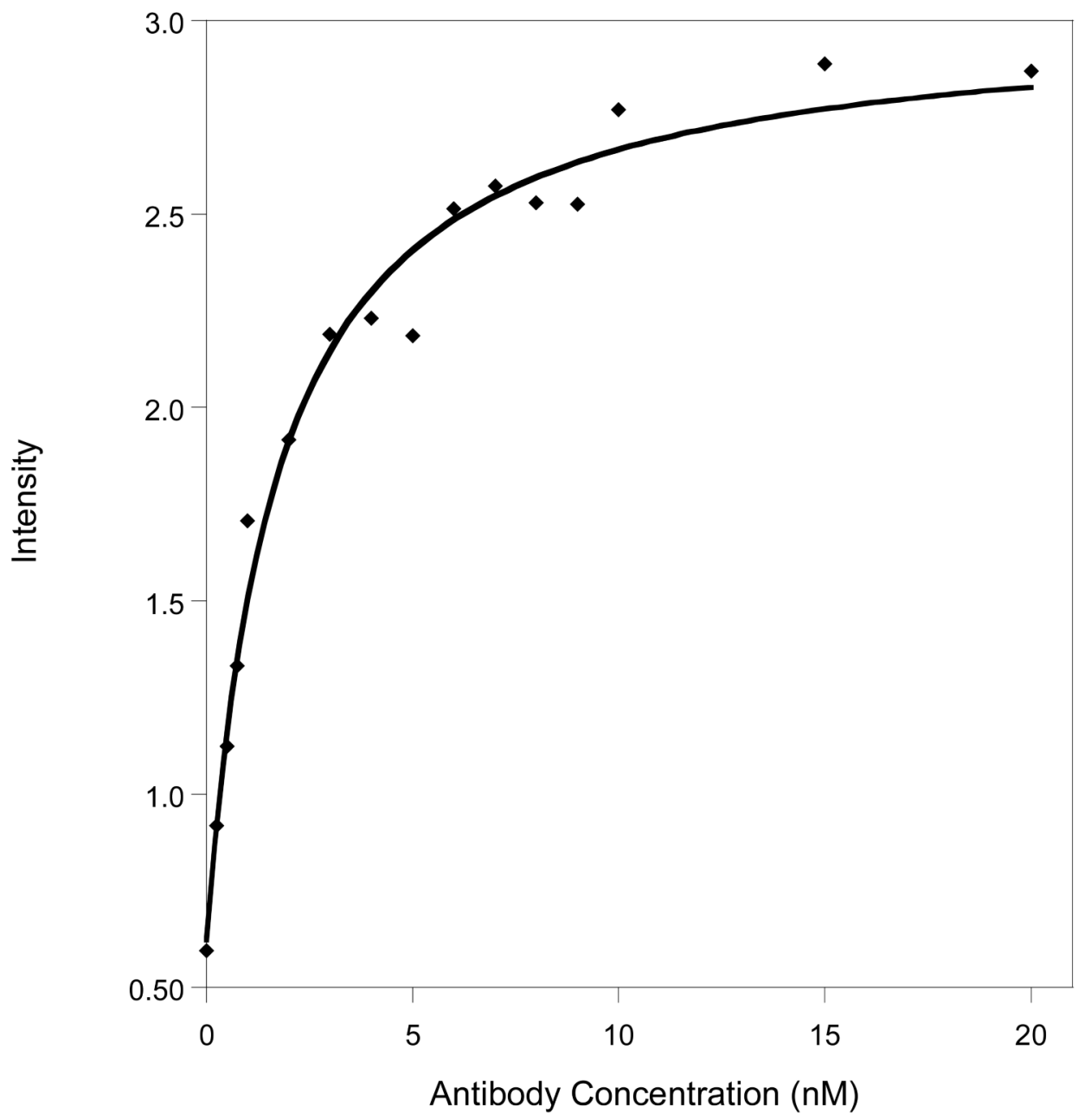

Figure 2.

The emission of the PB increases approximately six-fold upon target binding. Shown are data collected in buffer at a PB concentration of $1 \mathrm{nM}$. 

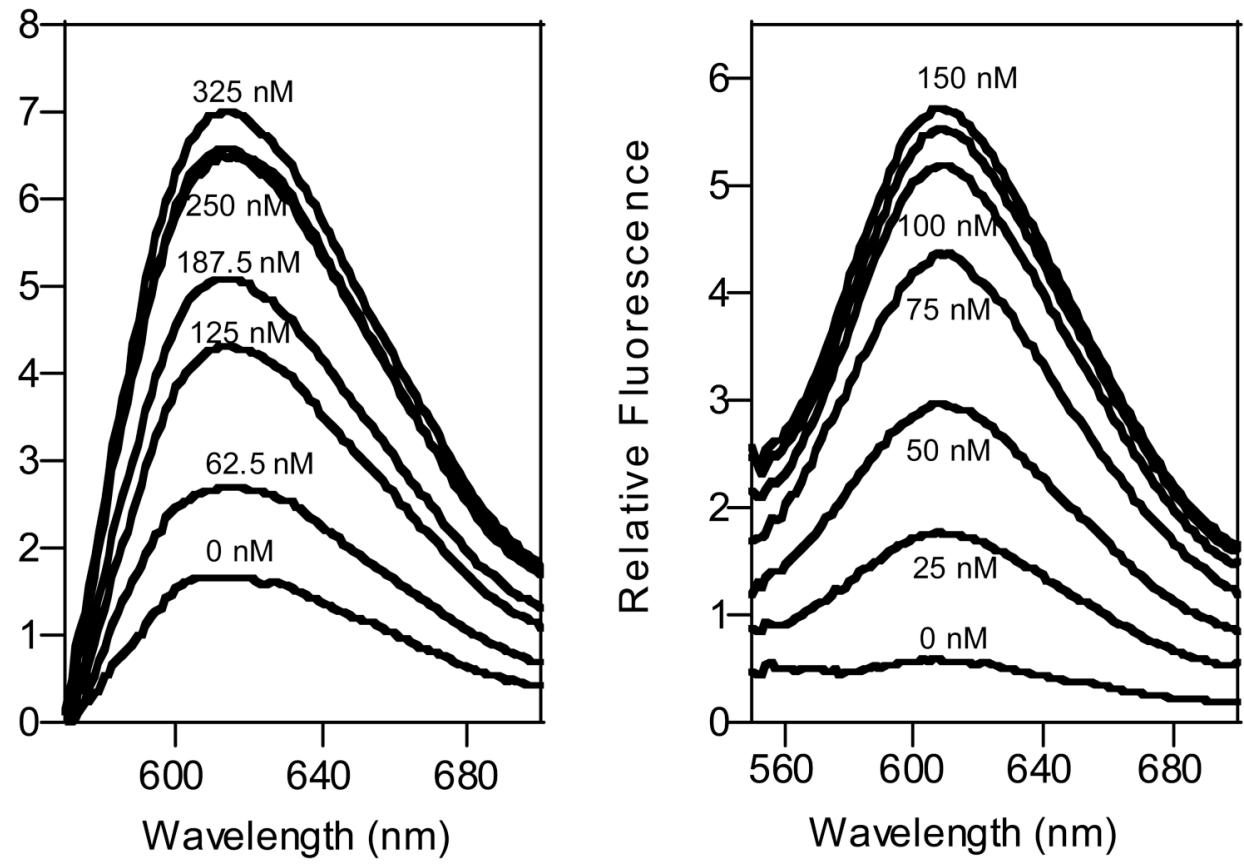

Figure 3.

The PB approach is selective to work even in grossly contaminated samples in the backgroundsubtracted spectra of (left) $250 \mathrm{nM}$ PB in 50\% serum and (right) $100 \mathrm{nM}$ PB in saliva. 